\title{
Trends in the Vertical Distribution of Ozone
}

\author{
William J. Randel \\ National Center for Atmospheric Research \\ Boulder, CO 80307 \\ Richard S. Stolarski \\ NASA Goddard Space Flight Center \\ Greenbelt, MD 20771 \\ Derek M. Cunnold \\ Georgia Institute of Technology \\ Atlanta, GA 30332 \\ Jennifer A. Logan \\ Harvard University \\ Cambridge, MA 02138 \\ M. J. Newchurch \\ University of Alabama in Huntsville \\ Huntsville, AL 35899
}

December 1998

Submitted to Science 


\begin{abstract}
Recent reanalyses of satellite, ground-based and balloon measurements allow updated estimates of trends in the vertical profile of ozone during 1980-96. The results show overall consistency between several independent measurement systems, particularly for northern hemisphere mid-latitudes where most ground-based measurements are made. Combined trend estimates over these latitudes show statistically significant negative trends at all altitudes between 10 and $45 \mathrm{~km}$, with two local maxima: $-7.4 \pm 2.0 \% /$ decade at $40 \mathrm{~km}$ and $-7.6 \pm 4.6 \%$ /decade at $15 \mathrm{~km}$ altitude. There is a strong seasonal variation in trends over northern mid-latitudes in the altitude range of $10-18 \mathrm{~km}$. The profile trends are in quantitative agreement with independently measured trends in column ozone.
\end{abstract}


The distribution and trends in atmospheric ozone affect the climate system in several ways. Ozone strongly absorbs solar ultraviolet (UV) radiation, so that a reduction in ozone results in increased UV radiation levels in the troposphere and at the Earth's surface. These increased UV levels are associated with increases in tropospheric photochemical reactivity, which directly influences tropospheric $\mathrm{CO}$ and $\mathrm{CH}_{4}$ trends (5).

Ozone also absorbs and emits infrared radiation, and it is an effective greenhouse gas. Changes in stratospheric ozone concentration strongly affect the temperature of the stratosphere itself, and also have a direct impact on the troposphere. Recent estimates suggest that up to $30 \%$ of the surface warming due to greenhouse gas increases since 1980 may have been offset by the cooling effects of ozone loss (6). In order to accurately assess and model the impacts of the recent decadal changes in ozone, knowledge of the vertical structure of the trends is crucial. Additionally, knowledge of the vertical distribution of trends is critical for attribution of causes for these trends; indeed, one of the largest uncertainties in determining the effect of anthropogenic chlorine on stratospheric ozone has been the magnitude of trends in the altitude region between 15 and $20 \mathrm{~km}$.

\section{Sources of data}

No uniform data source exists to allow global estimation of long-term changes in the vertical ozone distribution. The data available for trend studies come from a number of ozone measuring platforms, which use different sensing techniques with varying spatial and temporal coverage. Four different measurement systems have produced records long enough to assess long-term ozone trends. A network of stations provides 
Satellite measurements of the vertical profile of stratospheric ozone have been made by the Stratospheric Aerosol and Gas Experiment (SAGE) (9). SAGE I data are available from February 1979 until November 1981. SAGE II began operation in October 1984, and continues to make measurements to the present. The SAGE measurement technique is based on solar occultation, with profile measurements obtained at sunrise and sunset on each of 14 orbits in a day. This measurement technique provides good vertical resolution $(\sim 1 \mathrm{~km})$ and very small long-term drift due to instrument calibration, but spatial sampling is limited so that it takes approximately one month to sample the latitude range $60^{\circ} \mathrm{N}-\mathrm{S}$. A difficulty in combining the SAGE I and SAGE II ozone measurements for trend studies arises from an apparent error in the reference altitude for SAGE I. An empirical altitude correction has been applied to SAGE I data in an attempt to remove this bias (10). The SAGE II data used here are from retrieval version 5.96, with special attention paid to removing aerosol contamination effects in the lower stratosphere. Because problems remain during periods of exceptionally high aerosol loading, SAGE II data are not used in the lower stratosphere for $1-2$ years following the eruption of Mt. Pinatubo in 1991 (4).

The SAGE I/II and ozonesone data are the primary data for evaluation of trends in the lower stratosphere (below $25 \mathrm{~km}$ ), and the SAGE global coverage complements the more reliable but spatially isolated sonde measurements. Although past comparisons have indicated substantial differences between trends derived from sonde and SAGE measurements (3), comparisons based on the revised SAGE and sonde data here show good agreement (as shown below). Furthermore, detailed comparisons between SAGE II and all available data sets by the SPARC/IOC assessment demonstrated no systematic 


\section{Trends in the upper stratosphere}

The upper stratosphere (altitudes between about 30 and $50 \mathrm{~km}$ ) is a region where changes in ozone were originally predicted to occur due to anthropogenic chlorine increases (12). At these altitudes the chemistry should be dominated by gas-phase reactions. Trends above $30 \mathrm{~km}$ can be derived from SAGE I/II, SBUV(/2) and Umkehr data (13), and Fig. 1 shows a comparison of trends from these data over $40-50^{\circ} \mathrm{N}$ (where results from Umkehr stations at Boulder, Haute Provence and Belsk are averaged). As shown in Fig. 1, statistically significant negative trends are observed in all three data sets over $30-45 \mathrm{~km}$, with peak values of -6 to $-8 \%$ per decade near $40 \mathrm{~km}$. There is good agreement between SAGE I/II and Umkehr results, while the SBUV(/2) combined record shows less negative trends (but less confidence is placed in these data as discussed above).

A global cross-section of trends derived from the combined SAGE V/II data is shown in Fig. 2 (14). Statistical standard errors for these annual mean trend results are of order $0.2 \%$ per year. Statistically significant negative trends are seen in the upper stratosphere (35-45 km), with maxima of order $-8 \%$ per decade over middle-high latitudes of both hemispheres. Trends in the tropical upper stratosphere are less negative and not statistically significant, and overall there is remarkable global symmetry in the trends above $30 \mathrm{~km}$. The SAGE I/II trends in Fig. 2 show a relative minimum over altitudes $25-30 \mathrm{~km}$, and increased negative trends in the lower stratosphere. The magnitude of the upper stratospheric ozone loss and the spatial pattern of maxima over high latitudes seen in Fig. 2 is consistent with idealized model calculations of ozone loss 
approximately the same period (18). These data both show statistically significant negative trends over $20-25 \mathrm{~km}$. The averaged ozonesonde trends in this region are somewhat more negative than zonal mean SAGE results, although they agree within 2 sigma uncertainty levels. This approximate agreement in the lower stratosphere is a significant improvement over previous comparisons (3), mainly due to the inclusion of the latitude-dependent altitude correction to SAGE I data. Trends calculated from SAGE II data only (spanning 1984-96) allow extension of the trends down to $15 \mathrm{~km}$, and comparisons with sondes over northern hemisphere midlatitudes shows good agreement (19). The SAGE II data over $15-20 \mathrm{~km}$ in the tropics (not shown) exhibit much more negative trends than in northern midlatitudes, and there are strong positive trends in the southern hemisphere. However, the trends are not statistically significant in either of these regions, and there are insufficient tropical or southern hemisphere sonde records with which to compare these results.

Averaging the ozone sonde trends over the seven stations (Fig. 5) reveals large seasonal variation between 10 and $18 \mathrm{~km}$ altitude, with maximum negative trends during northern hemisphere winter and spring. Relatively little seasonal variation is observed above $20 \mathrm{~km}$. The exact time dependence of the seasonal variation over $10-18 \mathrm{~km}$ depends on location: European stations show a winter-spring maximum, while Canadian stations show a spring-summer maximum (17).

The ozone trends in Fig. 5 are expressed in terms of ozone density tendency, rather than percent tendency (as in Figs. 1-4), in order to quantify contribution to the column ozone trends (note the very small ozone density trends near $40 \mathrm{~km}$ seen in Fig. 5 , in spite of the relatively large percentage trends seen in Fig. 2). The vertical integral of 


\section{Summary}

Trends in the vertical distribution of ozone have been calculated from four different measurement systems. Trends in the upper stratosphere show consistent magnitudes between SAGE I/II and Umkehr data, with SBUV(/2) slightly less negative. In the lower stratosphere reasonably consistent trends are found between SAGE I/II and ozonesonde data over $20-27 \mathrm{~km}$ for northern mid-latitudes. There is thus overall good agreement between the various ground-based and satellite measurement systems.

An overall ensemble estimate of the ozone trends over northern midlatitudes is shown in Fig. 7. Results from all four measurement types are incorporated in the figure; the uncertainties are based on combined statistical and instrumental drift uncertainties (21). Because of the large geographic variability in tropospheric trends (Fig. 3) it is not reasonable to produce a mean troposphere estimate, and ensemble results are not included below $10 \mathrm{~km}$ in Fig. 7. Trends in northern midlatitudes from the combined analyses show statistically significant negative trends over all altitudes between 10 and $45 \mathrm{~km}$. The combined trend has two local extremes, $-7.4 \pm 2.0 \%$ per decade at $40 \mathrm{~km}$, and $-7.6 \pm$ $4.6 \%$ per decade at $15 \mathrm{~km}$. A minimum trend of $-2.0 \pm 1.8 \%$ per decade is deduced at 30 $\mathrm{km}$. The major contribution to the $\mathrm{NH}$ midlatitude column ozone decline during the last two decades has come from decreases in the lower stratosphere (16). The results here furthermore demonstrate a consistency between the vertically integrated sonde data and independent column ozone trends, in terms of both magnitude and seasonal variation (Fig. 5). Our understanding of ozone trends over the period 1980-96 has thus reached an improved level of understanding, at least for observations over northern midlatitudes. 


\section{$\underline{\text { References and Notes }}$}

1. R. Stolarski, R. Bojkov, L. Bishop, C. Zerefos, J. Staehelin, J. Zawodny, Science, 256, 342 (1992); R. McPeters, S. Hollandsworth, L. Flynn, J. Herman, C. Seftor, Geophys. Res. Lett., 23, 3699 (1996); S. Hollandsworth, R. McPeters, L. Flynn, W. Planet, A. Miller, S. Chandra, Geophys. Res. Lett., 22, 905 (1995).

2. R. D. Bojkov, R. D. Hudson et al., in "Scientific Assessment of Ozone Depletion: 1998," World Meteorological Organization/United Nations Environmental Program Report No. 44, World Meteorological Organization, Geneva, Switzerland. Chap. 4.

3. N. Harris et al., in "Scientific Assessment of Ozone Depletion: 1994" World Meteorological Organization/United Nations Environment Program Report No. 37, World Meteorological Organization, Geneva, Switzerland, Chap. 1.

4. "Assessment of trends in the vertical distribution of ozone," Stratospheric Processes and their Role in Climate (SPARC) Report No. 1, World Meteorological Organization Global Ozone Research Monitoring Project Report No. 43, Geneva, 1998.

5. S. Madronich and C. Granier, Geophys. Res Lett., 19, 465 (1992); J.S. Fuglestvedt, J.E. Johnson and I.S.A. Isaksen, Tellus, 46B, 172 (1994);S. Bekki, K.S. Law and J.A. Pyle, Nature, 371, 595 (1996).

6. S.F. B. Tett, J.F.B. Mitchell, D.E. Parker and M.R. Allen, Science, 2741170 (1996); C. Granier, K. Shine et al., in "Scientific Assessment of Ozone Depletion: 1998," 
16. The maximum ozone density in the midlatitude stratosphere occurs over altitudes 15 $25 \mathrm{~km}$. Although mixing ratios of ozone are large over $20-50 \mathrm{~km}$, approximately $75 \%$ of the column ozone occurs below $30 \mathrm{~km}$ (because of exponentially decreasing atmospheric density with height).

17. J. A. Logan et al., J. Geophys. Res., submitted. Trends were derived from ozonesonde data spanning 1970-96 by two independent groups (J. Logan at Harvard University and G. Tiao at University of Chicago), and their results are in good agreement. These groups treated the sonde data somewhat differently prior to trend analysis, using different data selection criteria that affected the amount of data used in the analyses. See reference (4) for more detail. The sonde trend analyses shown here were conducted by J. A. Logan and I. A. Megretskaia of Harvard University.

18. The space-time sampling of SAGE measurements do not allow a sufficient number of direct overlap comparisons with individual ozonesonde time series. In order to minimize statistical uncertainties, available ozonesonde trends over northern midlatitudes (in Europe, North America and Japan) are averaged and compared to trends derived from zonal mean SAGE data.

19. D. M. Cunnold et al., J. Geophys. Res., submitted.

20. R. M. McPeters et al., Geophys. Res. Lett., 23, 3699 (1996).

21. Trends from each measurement type are derived with an associated estimate of statistical uncertainty. An additional uncertainty is that due to the potential drift of the instrument over time, and the total uncertainty is a root sum of squares addition of statistical and instrumental terms. These uncertainties have been evaluated for each instrument type (4). The average trends and uncertainty estimates in Fig. 7 are 


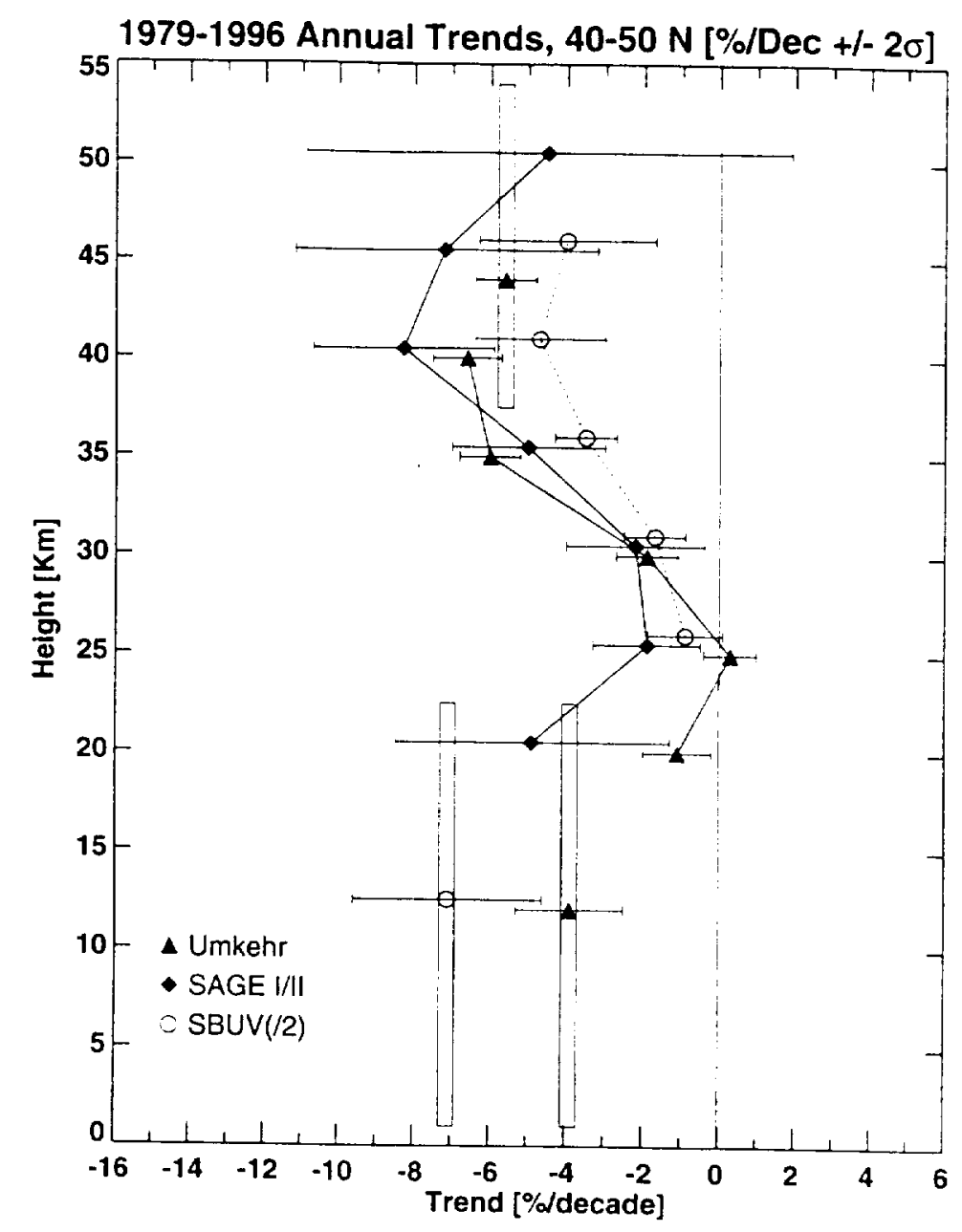

Figure 1. Ozone trends ( $\% /$ decade relative to the mean for the period) over $40-50^{\circ} \mathrm{N}$ for the period 1979-96, calculated from SAGE I/II and SBUV(/2) satellite data and for 3 Umkehr stations (Boulder, Haute Provence and Belsk). Vertical bars indicate thick layer retrievals for Umkehr and SBUV(/2). Horizontal errors bars show $95 \%$ confidence intervals of the trend; SAGE I/I error bars represent SAGE I altitude correction uncertainties, SAGE II sunrise/sunset trend difference uncertainties, and statistical uncertainties. Umkehr and SBUV(/2) error bars represent statistical uncertainty only. 


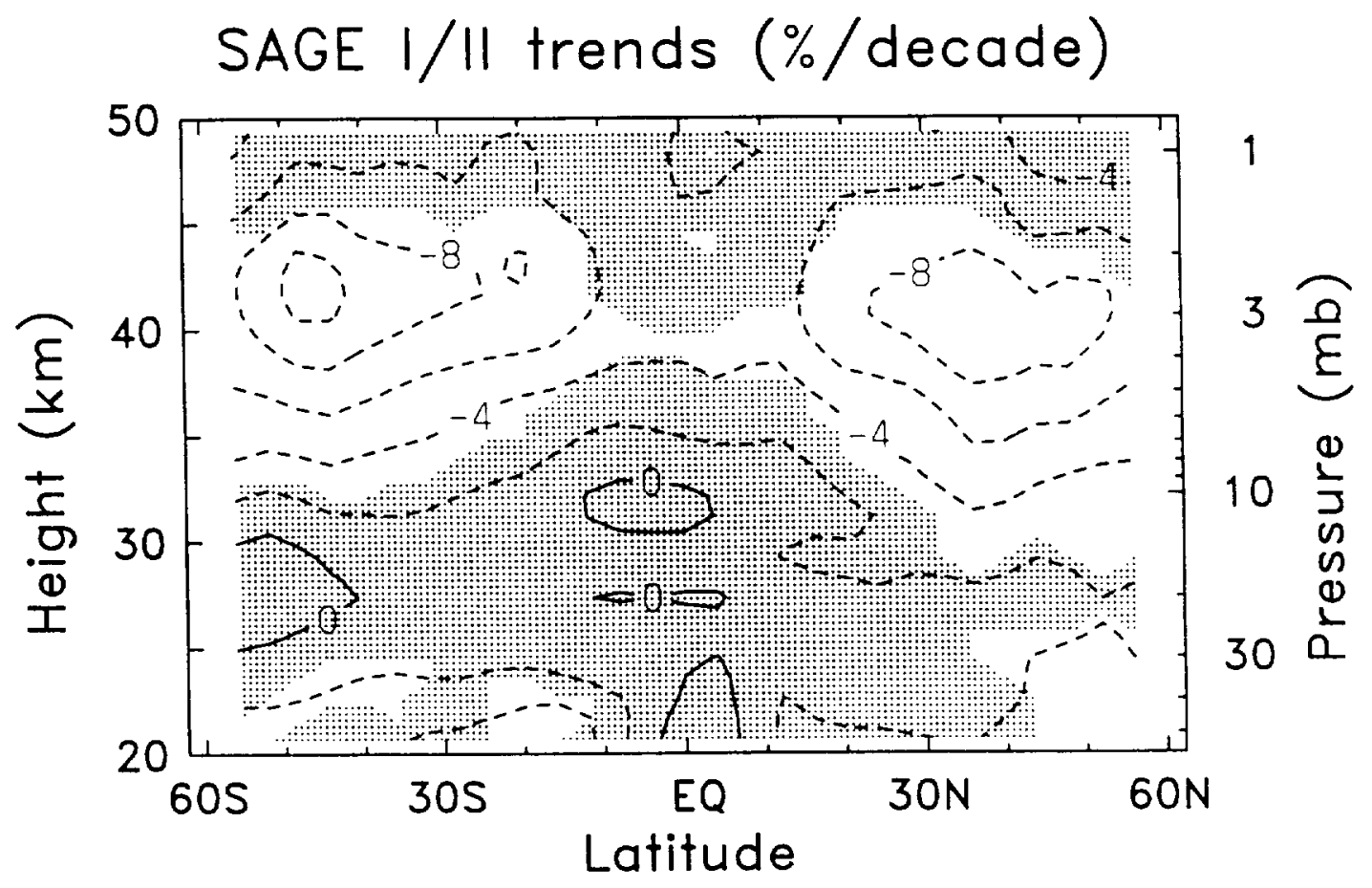

Figure 2. Annual mean ozone trends calculated from SAGE VII observations from 197996 , expressed in \%/decade of the mean of the time series. Results are contoured from calculations done in $4^{\circ}$ latitude bands and $1 \mathrm{~km}$ altitude intervals. Shading indicates where the trends are not different from zero within $95 \%$ confidence limits. 


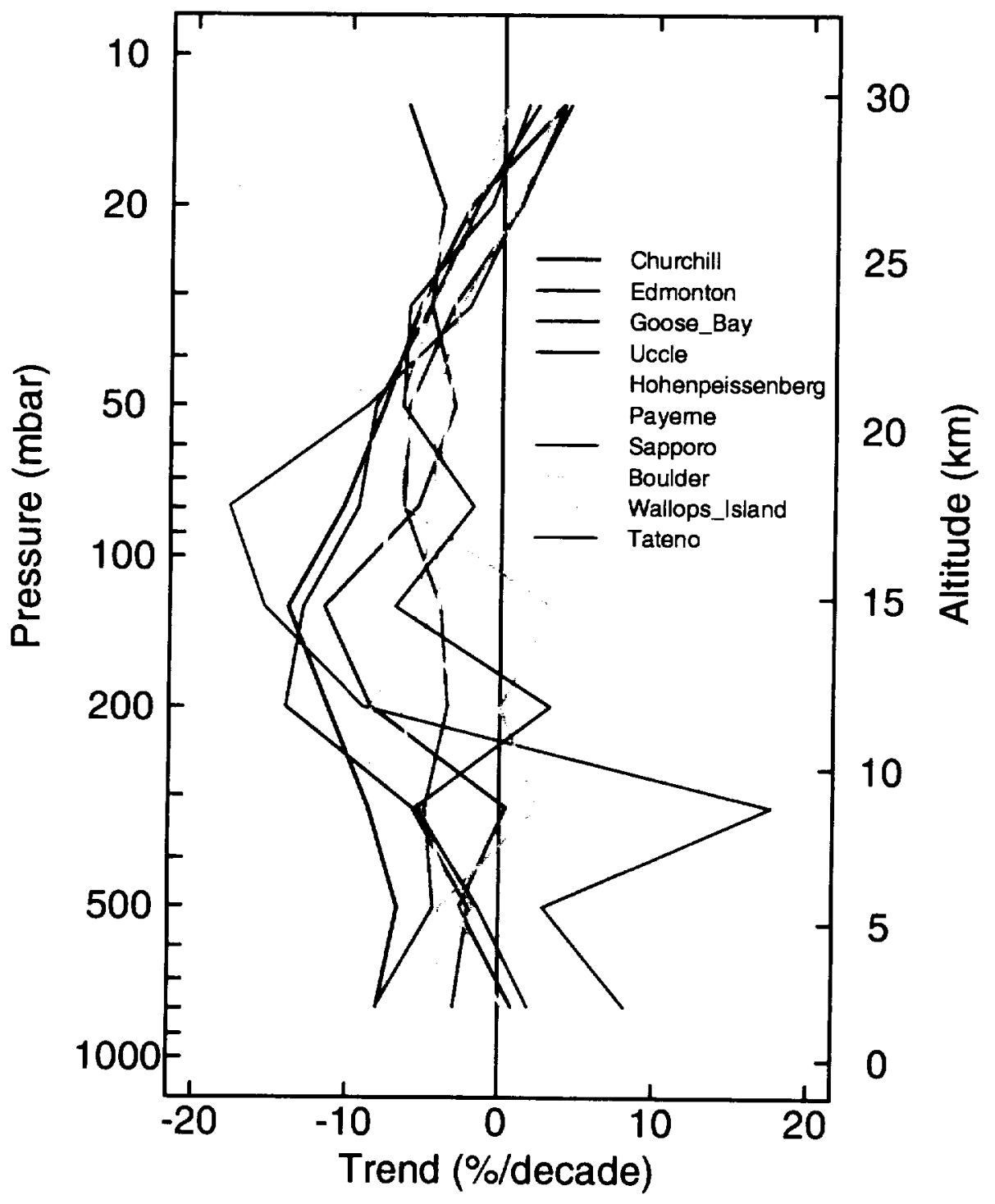

Figure 3. Annual trends in ozone over 1980-96 derived from ozonesonde measurements. Shown here are superimposed trend results for individual stations located between $36-59^{\circ} \mathrm{N}$. 


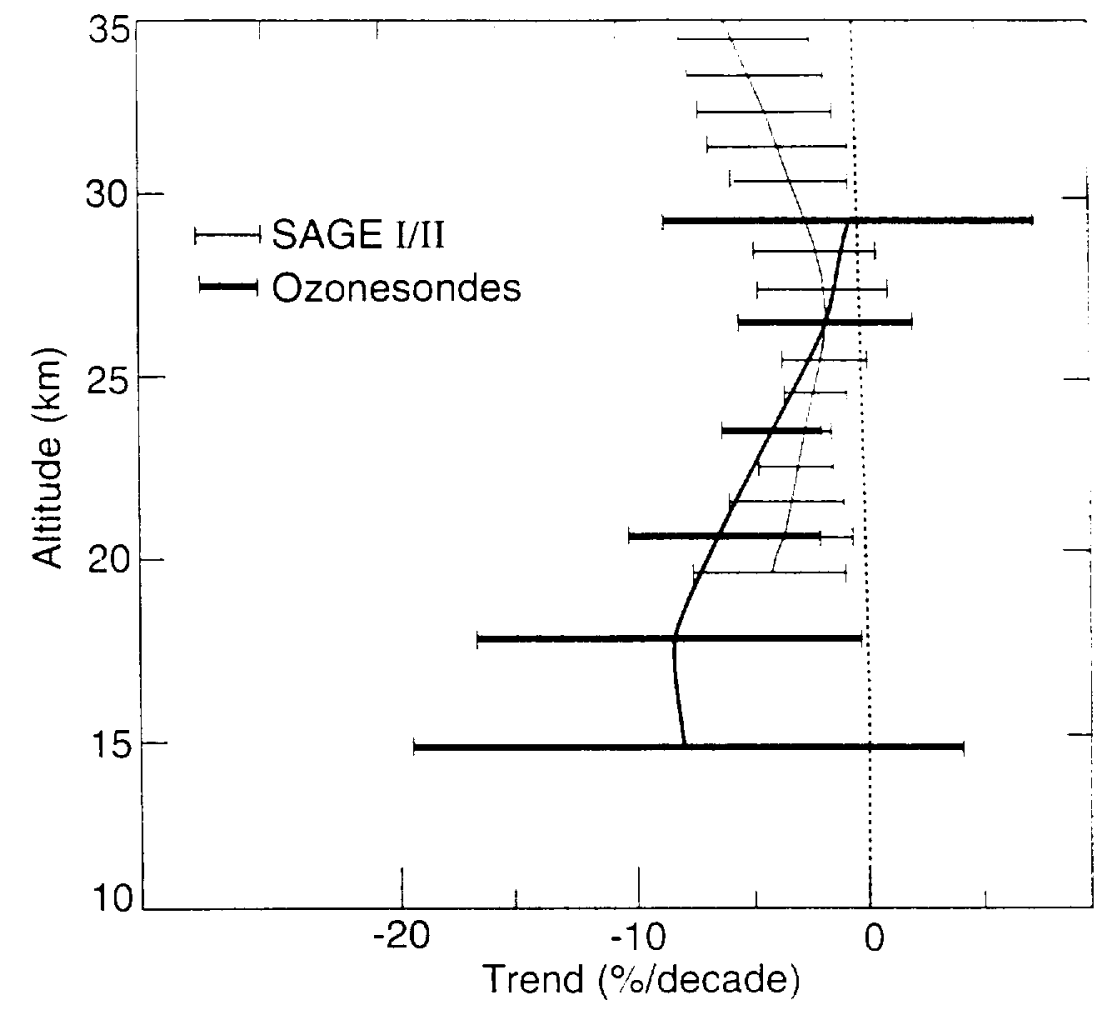

Figure 4. Average ozonesonde trends for Uccle, Hohenpeissenberg, Payerne, Edmonton, Goose Bay, Sapporo and Boulder $\left(40-53^{\circ} \mathrm{N}\right)$ for $1980-96$ in $\% /$ decade (darker lines), compared to zonal average SAGE $\mathrm{VII}$ trends over $45-50^{\circ} \mathrm{N}$ (lighter lines). Two sigma uncertainty levels are also included. 


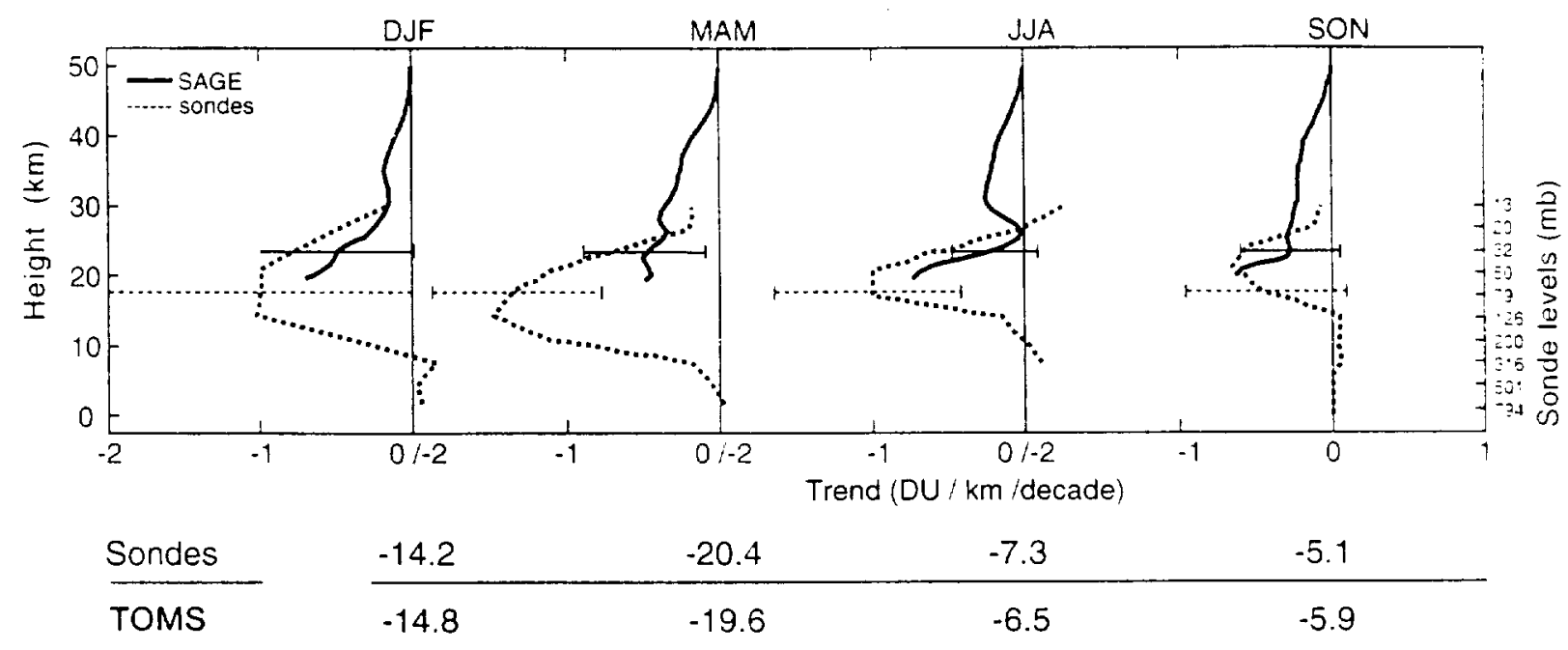

Figure 5. Altitude profiles of $1980-96$ ozone trends over $40-53^{\circ} \mathrm{N}$ for seasonal calculations (December-February, March-May, June-August, SeptemberNovember), showing SAGE $\mathrm{I} / \mathrm{II}$ and averaged ozonesonde results. Results are expressed in terms of ozone density tendency (Dobson Units (DU) $/ \mathrm{km} /$ decade). The column integrals of the ozonesonde trends over $0-30 \mathrm{~km}$ is listed at the bottom (with units of DU/decade), together with column ozone trends derived from TOMS satellite data. 


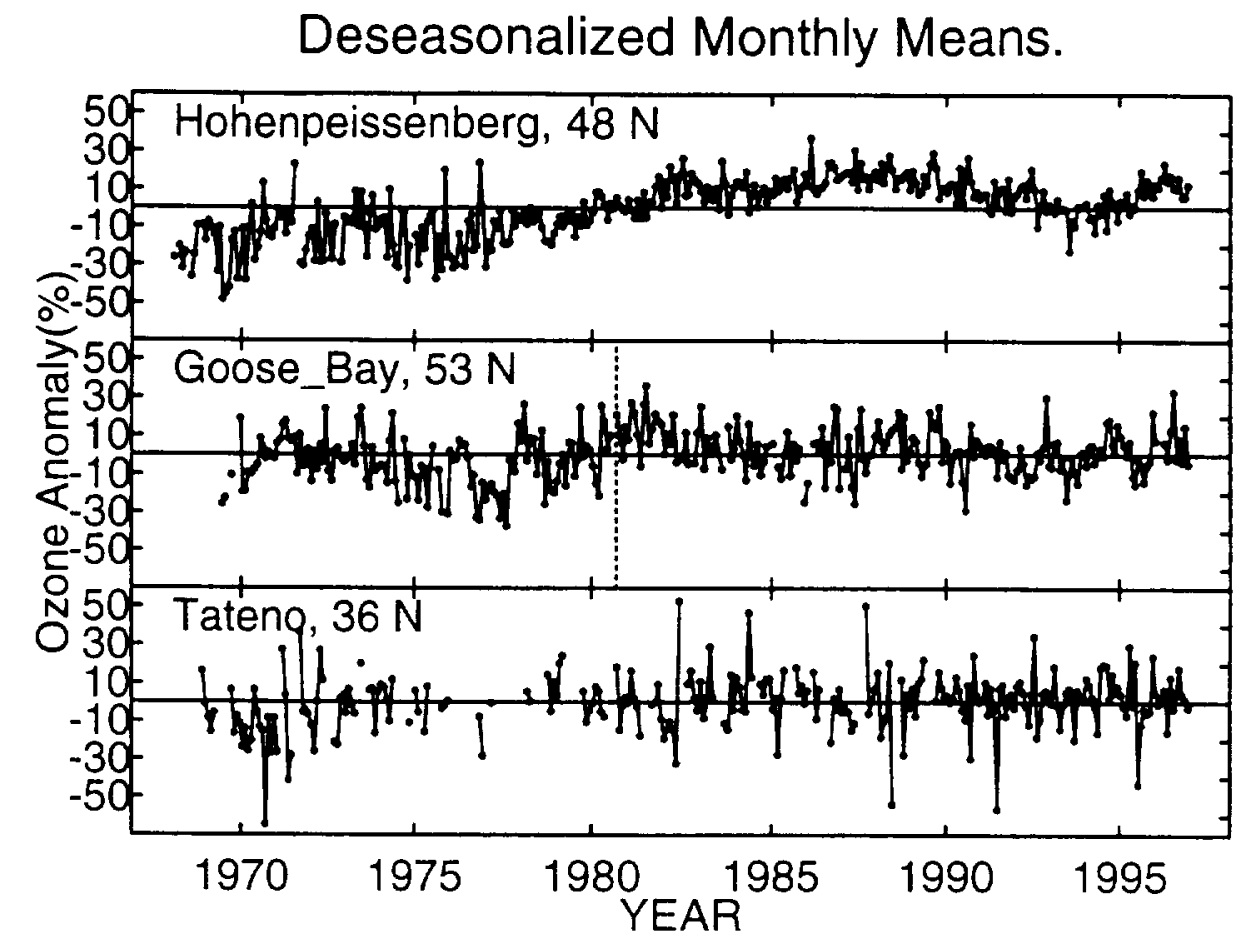

Figure 6. Deseasonalized time series of monthly mean ozone anomalies at $500 \mathrm{hPa}$ $(\sim 5 \mathrm{~km})$ for measurements at Hohenpeissenberg, Germany (top), Goose Bay, Canada (middle) and Tateno, Japan (bottom). Anomalies are expressed in terms of percentage change with respect to the long-term means. 


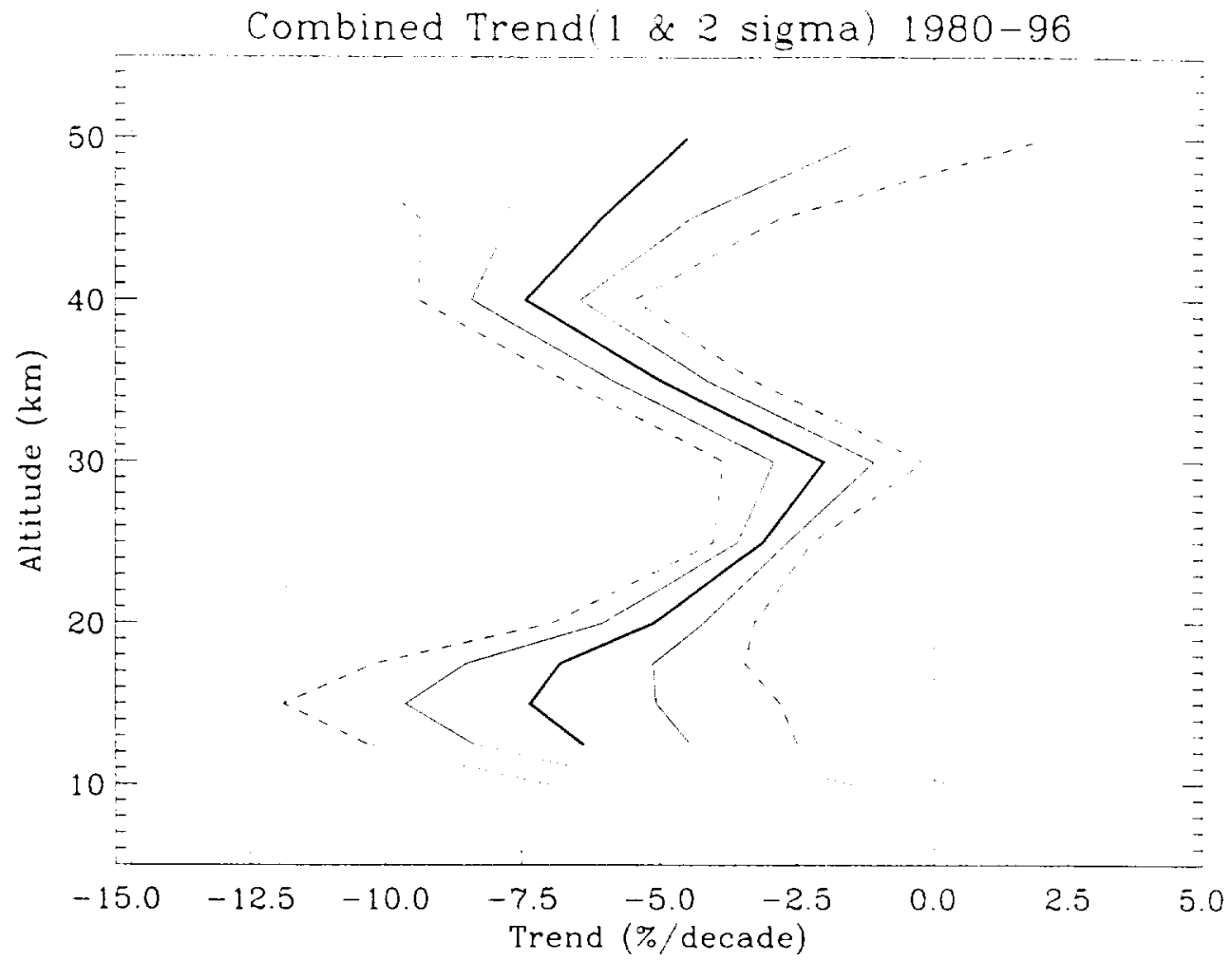

Figure 7. Estimate of the annual mean ozone trend over northern midlatitudes $\left(40-50^{\circ} \mathrm{N}\right)$ using combined satellite, balloon and ground-based measurement systems. Combined uncertainties are shown as $1 \sigma$ and $2 \sigma$ values. Combined trends have not been shown in the troposphere because the small sample of sonde stations have large additional uncertainty concerning their representativeness of mean trends. 